\title{
DIREITO DESPORTIVO E O \\ DIREITO AO DESPORTO NA \\ CONSTITUIÇÃO DA REPÚBLICA FEDERATIVA DO BRASIL
}

\section{Rafael Teixeira Ramos}

Mestre em Ciências Jurídico-Laborais pela Faculdade de Direito da Universidade de Coimbra (Portugal). Professor de Direito do Trabalho Desportivo. Advogado.

ramosrt@hotmail.com

Sumário: Introdução. 1) Direito Desportivo 2) Importância do desporto na sociedade moderna, uma influência para a sua constitucionalização 3) A constitucionalização do desporto no Brasil 4) Direito ao Desporto, porque um direito sócio-fundamental? 5) Direito ao Desporto 6) Ensino do Direito Desportivo/Direito do Desporto: uma urgência para a academia jurídica cearense. Considerações finais.

Resumo: O trabalho tem o objetivo principal de apresentar o direito desportivo à academia jurídica cearense, esclarecer a importância do desporto em nossa sociedade contemporânea, relatando os diversos valores do esporte e a motivação de sua previsão e proteção constitucional. Aborda-se a comprovação do desporto como um direito social fundamental. Explana-se resumidamente cada ponto e princípio do direito ao desporto no art. 217 da Constituição Federal. Destaca-se a urgência, clamor da introdução do ensino de Direito Desportivo/Direito do Desporto no magistério jurídico cearense.

Palavras-chave: Direito Desportivo; direito sócio-fundamental; direito ao desporto.

O desporto, como entidade multifuncional, individualmente, infunde nos homens a consciência de que, na vida, não há vitórias nem derrotas definitivas, e, socialmente, afigura-se como fenômeno de primeira magnitude e uma das mais significativas presenças do estilo de vida atual, sendo inconcebível ficar alijado ou ausente da nova Constituição. ${ }^{1}$

\footnotetext{
1 MELO FILHO, Álvaro. Desporto na nova constituição. Porto Alegre: Sergio Antonio Fabris Editor, 1990, p. 9.
} 


\section{INTRODUÇ̃̃o}

A Faculdade de Direito FA7 nos convidou para ministrar uma Palestra sobre Direito Desportivo/Direito do Desporto, com o objetivo de se abordar qualquer assunto do ramo. Nessa oportunidade, aproveitamos para apresentar a existência da disciplina, sua sustentação nuclear a partir da Constituição Federal e o direito ao desporto na própria Carta Magna.

Agradecemos primacialmente a Instituição pelo patrocínio da causa jurídicodesportiva, expressando ainda que a acadêmica jurídica cearense excepcionalmente prestigia o estudo, pesquisa, ensino do Direito Desportivo e conquistar esse espaço é uma honra, uma valia indimensionável para a evolução da academia jurídica do Estado do Ceará e para aqueles que, como nós, lutamos para a consolidação do Direito do Desporto no Brasil.

Nesse esboço, jamais poderíamos recusar o ilustre convite da coordenação do Curso de Direito da FA7 para redigirmos um artigo científico explorando o Direito do Desporto. Desse modo, esse trabalho advém da palestra "Direito ao Desporto na Constituição Federal", ministrada por nós no auditório do curso de Direito da FA7, o que não significaria excesso apontar tal modesto evento como pelo menos um registro histórico, uma atitude campeã do magistério jurídico da FA7.

\section{Direito Desportivo}

Direito Desportivo, denominação usual na academia jurídica brasileira ou Direito do Desporto, vocábulo comumente utilizado no ensino jurídico lusitano para se referir a disciplina do direito que envolve o estudo da fenomenologia jurídicoesportiva, é uma nomenclatura solene que se originou primeiro do costume de falar o idioma luso formalizado em meados do passado século XX no Brasil ${ }^{2}$, segundo porque na mesma época o ensino superior tinha rejeição ao "aportuguesamento" da palavra sport, cognata de origem anglo-saxônica, e, por último, no início dos estudos da legislação esportiva, período brasileiro de materialização inaugural do ramo jurídico-desportivo, existia uma necessidade de se distinguir o que era investigação meramente esportiva de investigação ius-desportiva.

No Brasil, contribuiu muito para o surgimento do Direito Desportivo/Direito do Desporto, a inicial normatização do esporte, desde o final da década de 1930, perpassando pelo decênio de 1940, momento histórico-político dominado pelo nazi-fascismo getulista. Neste instante, surgiram as primeiras edificações legislativoesportivas brasileiras, traçadas pela estatização corporativista da era Vargas. ${ }^{3}$

\footnotetext{
2 Relembramos um exemplo: nas primeiras décadas da prática do futebol no Brasil até fins dos anos 30', muitos brasileiros ainda chamavam a modalidade esportiva futebol de Ludopédio ou Balípodo.

${ }^{3}$ Decreto-Lei n. ${ }^{\circ}$ 1.056/39, Decreto-Lei n. ${ }^{\circ} 3.199 / 41$ e Decreto-Lei n. ${ }^{\circ} 5.342 / 43$.
} 
Na sequência, erigiram-se as duas primeiras leis esportivas caracterizadas pelo militarismo esportivo da ditadura militar ${ }^{4}$. Mais tarde, com o advento da democracia, momento crucial da constitucionalização do desporto, ${ }^{5}$ o Poder Legislativo iniciou a edição das Leis do período contemporâneo democrático. ${ }^{6}$

Hodiernamente, há uma tendência para a continuidade de instituição, modificação e diversificação em nossa legislação esportiva, pois para além do óbvio, permanece a necessidade de evolução legislativa no esporte brasileiro. ${ }^{7}$

Em paralelo a normação pública da atividade esportiva brasileira, algumas edições doutrinárias jusdesportivas emergiram pelo globo terrestre, referenciamos em primeira posição o francês Jean Loup ${ }^{8}$, ao publicar Les sports et le droit, depois os italianos Cesarini Sforza ${ }^{9}$ com a publicação de La teoria degli ordinamenti giuridici e il diritto sportivo em 1933, Massimo Severo Giannini ${ }^{10}$ com a pesquisa publicada nominalmente como «Prime osservazioni sugli ordinamenti giuridici sportivi» em 1949, o livro português de Arnaldo Constantino Fernandes ${ }^{11}$ «O Direito e os Desportos: breve estudo de direito desportivo» em 1946, ao passo que no Brasil, os doutrinadores precursores foram João Lyra Filho ${ }^{12}$ com a obramãe «Introdução ao Direito Desportivo» de 1952, Valed Perry ${ }^{13}$ com o seu livro «Comentários à Legislação Desportiva Brasileira» de 1965 e Álvaro Melo Filho ${ }^{14}$, autor de «Direito Desportivo» em 1983, o primeiro da sua série de 22 livros, recordista brasileiro em publicações de Direito Desportivo, quiçá do Mundo.

${ }^{4}$ Lei n. $^{\circ} 6.251 / 75$ e Lei n. $^{\circ} 6.354 / 76$.

5 Expressis verbis, arts. 24, IX e 217 da CF/88. Implicitamente, art. 6 da CF/88.

${ }^{6}$ Lei n. $^{\circ} 8.672 / 93$ revogada pela Lei n. ${ }^{\circ} 9.615 / 98$ alterada pelas Leis 9.981/00, 10.264/01, 10.672/03 e Lei n. ${ }^{\circ} 10.671 / 03$ (Estatuto de Defesa do Torcedor).

${ }^{7}$ Lei n. $^{\circ}$ 10.891/04 (Bolsa Atleta), Lei n. ${ }^{0} 11.345 / 06$ (Time Mania), Lei n. ${ }^{\circ}$ 11.438/06 (Incetivo ao Esporte), destacamos ainda o Projeto de Lei n. ${ }^{\circ}$ 5.186/05 que propõe modificação da Lei n. ${ }^{\circ}$ 9.615/98 (Lei Pelé) e que o Presidente Lula já assinou e enviou projetos ao Poder Legislativo para alteração do Estatuto de Defesa do Torcedor, bem como o Ministério Público paulista movimenta uma campanha para implementar uma Lei Penal Desportiva, em que se tipificaria criminalmente algumas condutas antidesportivas já sancionáveis na seara punitiva-desportiva, tais como: manipulação de resultado, venda ilegal de ingressos (cambismo de ingressos), invasão de campo e em certos casos, o doping/dopagem atlética.

8 LOUP, Jean. Les sports et le droit. Paris: Dalloz, 1930.

9 SFORZA, Cesarini apud MEIRIM, José Manuel. A federação desportiva como sujeito público do sistema desportivo. Coimbra: Coimbra Editora, 2002, p. 57.

${ }^{10}$ GIANNINI, Massimo Severo apud MEIRIM, José Manuel. Temas de direito do desporto. Lisboa: Coimbra Editora, 2006, p. 254.

${ }^{11}$ FERNANDES, Arnaldo Constantino apud MEIRIM, José Manuel. O direito do desporto em Portugal: uma realidade com história. In: BARBOSA, Nuno; COSTA, Ricardo. I Congresso de direito do desporto. Coimbra: Almedina, 2005, p. 34.

${ }^{12}$ YRA FILHO, João. Introdução ao direito desportivo. Rio de Janeiro: Pongetti, 1952.

${ }^{13}$ PERRY, Valed. Comentários à legislação desportiva brasileira. Disponível em: «http://www.estantevirtual. com.br/buscaporautortitulo/». Acesso em 29 abr. 2009.

${ }^{14}$ MELO FILHO, Álvaro. Direito desportivo. Fortaleza: IOCE, 1983. 
Afora o delineado acima, as contumazes críticas ao longo das três últimas décadas sobre a existência do Direito Desportivo, de certa forma, propiciou o desenvolvimento em derredor da matéria jurídico-desportiva, na medida em que muito se discutia e se pesquisava acerca da possibilidade de existir pureza na positivação esportiva, bem como no conteúdo jurídico da materialidade desportiva.

Em decorrência da dificuldade de configurar os entornos materiais purificados da Disciplina de "Direito do Desporto", muitos juristas suscitaram a inexistência do "Direito Desportivo", argumentado que esta matéria não teria sustância própria e sempre seria acessória de outras matérias do Direito, tais como: Direito Constitucional Desportivo, Direito do Trabalho Desportivo, Direito Civil Desportivo, Direito do Consumidor Desportivo, etc. Esta seria a nominada teoria apura do Direito Desportivo.

Não obstante, logo exsurge o segmento teórico de oposição, em que se defende a existência pura do Direito Desportivo (teoria pura), sendo a sua natureza originária, consubstanciada no direito ao desporto, na regulação da atividade esportiva, na normogênese da organização das competições desportivas e seus métodos disciplinares, na normativa, estruturação e condução da Justiça Desportiva (Justiça Especializada).

A vertente teórica mais moderna abrange os dois ideais supramencionados, a nomeada teoria mista (híbrida) prescreve o Direito Desportivo como uma disciplina, ramo específico que envolve amplamente tanto a matéria purificada do Direito do Desporto, explicada acima, quanto os assuntos atrelados a outras áreas do Direito. ${ }^{15}$

$\mathrm{Na}$ atualidade a crise existencial do Direito Desportivo parece sepultada, pois com a explosão, combustão de regimes jurídicos especiais no Direito, se assentaram novos campos, como o Direito Ambiental, Direito Penitenciário, Direito Funerário, se cogita até em Direito das Águas, sendo cediço que o Direito do Desporto é dotado de materialidade própria, fenomenologia autêntica, realidade específica, sem estar desprovido de uma natural interdisciplinariedade também exclusiva que insere nos ramos tradicionais do Direito, contornos exclusivos, prevalecendo o seu estudo em disciplina própria. ${ }^{16}$

Realce-se mais uma vez o descrito anteriormente, que o Direito Desportivo possui quadro legislativo específico, doutrina ${ }^{17}$ e sua Justiça especializada que profere a sua jurisprudência.

${ }^{15}$ Indicamos para maiores pesquisas no tema: CASTRO, Luiz Roberto Martins. A natureza jurídica do direito desportivo. Revista Brasileira de Direito Desportivo. São Paulo: Editora OAB/SP, n. 1, p. 11-17, jan/jun, 2002.

${ }^{16}$ Segundo o Mestre Valed Perry: “O Direito Desportivo é uma realidade.” In PERRY, Valed. O Direito Desportivo. Revista Brasileira de Direito Desportivo. São Paulo: Editora OAB/SP, n. 1, p. 18-26, jan/jun, 2002.

${ }_{17}$ Por experiência própria, é bastante comum na Europa, com maior intensidade nos países latinos, encontrarmos em livrarias jurídicas, secção específica para os livros de Direito do Desporto. 
Ademais, as pesquisas de Direito Desportivo não são mais aventuras acadêmicas como se pensava há algumas décadas, existe um número cada vez mais exponencial de pesquisadores no ramo, dir-se-á até mesmo que está em voga o jurista consagrado escrever e publicar no terreno jusdesportivo, há o fomento de debates, palestras, simpósios, congressos, dentre outras promoções discursivas, além de se verificar um alvorecer de cursos extensivos, cursos de pós-graduação, tanto lato sensu, quanto stricto sensu. ${ }^{18}$

Enfim, declaramos ser indiscutível a existência do Direito Desportivo e o conceituamos: ciência jurídica autônoma, provida de autenticidade principiológica e normativa do fenômeno esportivo, englobando as suas materialidades naturais e interdisciplinares que disciplinam as diversas temáticas jurídicas desportivas. ${ }^{19}$

\section{IMPORTÂNCIA DO DESPORTO NA SOCIEDADE MODERNA, UMA INFLUÊNCIA PARA A SUA CONSTITUCIONALIZAÇÃO}

A prática e o desenvolvimento da atividade esportiva estão entrelaçados à própria existência da humanidade, desde as primeiras civilizações humanas, se transcorrendo pela civilização grega, romana, civilização da idade

${ }^{18}$ É visível que, desde o advento do art. 217 por força do qual insculpimos o desporto na Constituição Federal, brotaram inúmeras leis em matéria desportiva - foram 8 nos últimos oito anos - paralelamente a uma vasta produção jurídico-científica expressa em livros, monografias, teses e artigos, com destaque para a Revista Brasileira de Direito Desportivo, agora publicada pela prestigiosa Thomson/IOB, jungida à inescondível proliferação de jurisprudência extrajudicial e judicial em derredor de candentes temáticas jus-desportivas que ocupam expressivos espaços na mídia especializada.

Aduza-se que os cursos jurídicos, de um lado, passaram a implantar o Direito Desportivo como especialidade docente e investigadora, vale dizer, como disciplina autônoma integrante dos currículos plenos de Graduação, e, de outro, abrem espaços a cursos de pós-graduação lato sensu (aperfeiçoamento/especialização) com o propósito de aprofundar os estudos em derredor do binómio desporto/direito. E a sedimentação do Direito Desportivo é fortalecida, ainda, por sucessivos seminários e congressos nacionais e internacionais, cumulados a plúrimas atividades desenvolvidas pelo Instituto Brasileiro de Direito Desportivo (IBDD) e pela criação de Comissões jus-deportivas no âmbito do Ministério do Esporte e do Conselho Federal da OAB, além de incontáveis sites, blogs e listas de discussão na Internet dedicados ao Direito Desportivo. MELO FILHO, Álvaro. Direito desportivo brasileiro: retrospectiva e perspectiva. Desporto \& Direito: revista jurídica do desporto. Coimbra: Coimbra Editora, n. 8, p. 261-276, jan/abr, 2006.

${ }^{19}$ Em assimilada conceituação, Andrés Gil Domínguez averba: El derecho del deporte es la disciplina que se encarga de abordar el fenómeno deportivo desde las distintas vertientes del derecho, y a la vez posibilita generar intercambios interdisciplinarios que permiten analizar con mayor amplitud y riqueza cientifica todas las manifestaciones del objeto de estúdio: el deporte. DOMÍNGUEZ, Andrés Gil. El derecho al deporte y el derecho del deporte. In: NAVÍA, Ricardo Frega. Cuadernos de derecho deportivo. Buenos Aires: Ad Hoc, 2001, p. 34. 
média, até se imergir na sociedade moderna, o desporto se transfundiu numa multifuncionalidade social, política, econômica, cultural, universal, e, consequentemente, também jurídica. ${ }^{20}$

O esporte é um exercício tão social, quanto qualquer outra ação humana, na dimensão individual estudos científicos atuais apontam a prática esportiva como objeto de bem-estar psicofísico e coletivo, ou seja, biologicamente, com a atividade desportiva, o corpo humano produz substâncias que elevam a autoestima do indivíduo, além de sociologicamente inclúi-lo na comunidade. ${ }^{21}$

No aspecto coletivo, o desporto funciona como se não o maior, um dos maiores meios de inserção social e introspecção do espírito democrático no ser humano, uma vez que na atividade esportiva, há uma aproximação, convívio maior das diferentes classes sociais, as regras são rigidamente iguais para todos, pouco importando quem domina a política ou a economia, fator humanista para quem exercita esporte. Afora isso, a disciplina desportiva é indispensável para a manutenção das crianças e jovens na escola, auxílio na educação do homem e ensino escolar, ajuda na prevenção e recuperação da saúde da pessoa, infunde nos homens a democracia de conviver com as adversidades e saber superálas. ${ }^{22}$ Modernamente, o esporte ainda é uma das ferramentas mais poderosas no combate ao racismo, a xenofobia, as drogas, ao tráfico ilícito de entorpecentes (estupefacientes) e um dos melhores métodos de prevenção da violência em geral.

$\mathrm{Na}$ face política, em que pese a utilização histórica do esporte como uma manobra de opressão ideológica (Nazismo, Fascismo, Comunismo) e manipulação das massas (Ditadura Vargas, Ditadura Militar, algumas condutas governamentais flagrantes até hoje), a raiz politizada do esporte atual prega totalmente o oposto, que é a paz, a solidariedade, a unidade, todos idealizados num plano de políticas públicas que se destinam a reduzir as desigualdades sociais, o repúdio à criminalidade e a tentativa de colaborar na erradicação da miséria.

$\mathrm{Na}$ esfera econômica, segundo Simon Gardiner, "Sport is now big business ${ }^{\prime 23}$, significa em termos de atualidade, que a nomeada Indústria do Esporte

${ }^{20}$ A respeito da multifacetada natureza do desporto, o insigne mestre Álvaro Melo Filho discorreu em MELO FILHO, Álvaro. Novo ordenamento jurídico-desportivo. Fortaleza: ABC Fortaleza, 2000, p. 23-26.

${ }^{21}$ Exemplo de análise científica acurada em RIBEIRO, Carla. Desporto para todos - crise de identidade e desenvolvimento. In: BENTO, Jorge Olímpio; COSTANTINO, José Manuel. Em defesa do desporto: mutações e valores em conflito. Coimbra: Almedina, 2007, p. 317-355.

${ }^{22}$ Sustenta a nossa tese, Alexandra Pessanha: No sentido lato do termo, o desporto favorece o próprio processo de socialização, na medida em que estimula as qualidades sociais positivas e concorre, a par de outros factores, para o desenvolvimento harmonioso da personalidade. Enquanto espaço cultural, ele é dominado por um sistema de valores inerentes à prática de uma qualquer disciplina desportiva. O respeito por outrem, a solidariedade, o espírito de disciplina, nomeadamente, são valores que se transmitem à convivência social e, nessa medida, o desporto constitui um importante vector de tolerância, de identidade e de coesão social. PESSANHA, Alexandra. As federações desportivas: contributo para o estudo do ordenamento jurídico desportivo. Lisboa: Coimbra Editora, 2001, p. 15-16.

${ }^{23}$ GARDINER, Simon et al. Sports Law. 3. ed. Sydney/London: Cavendish, 2006, p. 37. 
ocupa no cenário da economia mundial uma posição de destaque, primordialmente nos séculos XIX e XX em alguns países anglo-saxões, continuamente em degraus avançados por todo o planeta ao longo do último centenário.

A exploração econômica do "espetáculo esportivo", o exercício formal e informal da economia em todos os entornos da "prática e do evento desportivos", e, consectariamente, a profissionalização esportiva posicionaram a Economia Desportiva no topo da Indústria do Entretenimento, sendo o mercado desportivo uma das maiores potencialidades de consumo, portanto, imaginar o Mundo sem desporto é querer imaginar uma involução da crise econômica globalizada que assola a população mundial.

No concernente ao caráter cultural, é cristalino que a própria naturalidade das modalidades desportivas conduz em seu seio uma sublime apresentação cultural, como é as acrobacias, baluartes, malabarismos e elasticidade visual da ginástica olímpica, nado sincronizado, ginástica rítmica, golfe, salto com vara, ou até mesmo o futebol. A simples atividade desportiva é uma expressão artística, uma manifestação cultural. Nesse contexto, há países criadores de esportes que refletem a cultura e os costumes do seu povo nas suas próprias atividades desportivas, é o exemplo da capoeira e do futsal, desportos genuinamente brasileiros, propagadores de muitos dos nossos caracteres consuetudinários. ${ }^{24}$

A universalidade está enraizada nas propriedades do desporto, enquanto elementos transcendentais aos limítrofes territoriais, permeadores da leveza da paz através de suas regras unidimensionais e promotores da unidade/união entres os povos praticantes. ${ }^{25}$

Em conclusão, o cariz jurídico-desportivo é precípuo para garantir a utilização do desporto como um dos principais vetores de evolução humana, um autêntico mecanismo beneficente à humanidade em todos os setores sobreditos $\mathrm{e}$ com a finalidade de resguardar a boa prática do direito ao esporte. ${ }^{26}$

\footnotetext{
${ }^{24}$ Curioso é se verificar o caso do futebol, que por força regulamentar da FIFA é rígido na preservação da nacionalidade dos atletas representantes na Copa do Mundo, aceitando a naturalização de jogadores para fins competitivos com restrição. Por tal medida, que sem muito esforço se percebe os tracejos culturas típicos em cada seleção de futebol durante a competição mundial da FIFA.

${ }^{25} \mathrm{Na}$ sociedade moderna, não há dúvida de que o desporto exerce grande influência no dia-a-dia dos cidadãos. Ademais, nenhuma nova realidade implantou-se com energia social e a universalidade do desporto, principalmente, quando percebemos que a FIFA congrega mais nações que a própria Organização das Nações Unidas (ONU); os materiais esportivos estão incorporados no cotidiano das pessoas; o espaço que o desporto ocupa na mídia; os eventos esportivos como Olímpiadas e Copas do Mundo, capazes de movimentar bilhões de pessoas, gerando empregos diretos e indiretos. EZABELLA, Felipe Legrazie. O direito desportivo e a imagem do atleta. São Paulo: IOB Thomson, 2006, p. 34.

${ }^{26}$ Para estudos mais intensificados sobre todas as figuras inerentes ao esporte moderno, incluindo o caráter jurídico, vide GARDINER, Simon et al., op. cit., 2006, p. 3 e ss.
} 


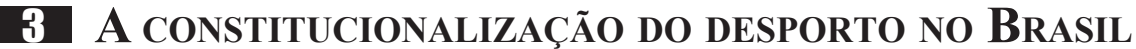

$\mathrm{O}$ esporte formal moderno, considerado aquele que se pratica com o fito de obter o melhor resultado, o primeiro lugar (ser o vencedor), não surge automaticamente como profissional e a retomada do exercício desportivo moderno no final do século XIX, inicialmente, não atrai a normatização pública, somente após a Segunda Guerra Mundial que o Estado timidamente começa a normatização do desporto, ao perceber todas as valências proporcionadas pela nomeada "sociedade esportivizada", todas prescritas no título anterior.

Nessa órbita, registre-se que a positivação constitucional do desporto foi bastante impulsionada pelos ciclos/dimensões evolutivas dos direito fundamentais de $2^{\mathrm{a}}, 3^{\mathrm{a}}$ e $4^{\mathrm{a}}$ gerações, destoando um pouco, com a devida data venia, do que preconizam os Mestres Paulo Bonavides, Gutiérrez, Bermejo e Álvaro Melo Filho $^{27}$, a constitucionalização desportiva, por ser um direito sócio-fundamental, parte da influência solidificada na consagração de outros direitos humanos, tais como: os sociais, culturais, econômicos, de isonomia, de solidariedade, de comunicação, ambiente saudável e sustentável, patrimônio comum da humanidade, autodeterminação e de pacificação entre os povos. Portanto, entendemos que o direito ao desporto não pode ser considerado um direito isoladamente proveniente da $2^{\mathrm{a}}$ geração, $3^{\mathrm{a}}$ dimensão, ou tão-somente da $4^{\mathrm{a}}$ geração, pois o nosso pensamento se aproxima da escola constitucionalista de Coimbra, sustentada na doutrina de Gomes Canotilho $^{28}$ jungida à tese de Vieira de Andrade ${ }^{29}$, ao transparecer que, na

${ }^{27}$ Verificar em MELO FILHO, Álvaro. Da constitucionalização do desporto no Brasil. Revista aranzadi de derecho de deporte y entrenimiento. Navarra: Thomson Aranzadi, n. 24, p. 263-271, 2008.

${ }^{28}$ Leciona Gomes Canotilho, É discutida a natureza destes direitos. Critica-se a précompreensão que lhes está subjacente, pois ela sugere a perde de relevância e até a substituição dos direitos das primeiras gerações. A ideia de generalidade geracional também não é totalmente correcta: os direitos são de todas as gerações. Em terceiro lugar, não se trata apenas de direitos com um suporte colectivo - o direito dos povos, o direito da humanidade. Neste sentido se fala de solidarity rights, de direitos de solidariedade, sendo certo que a solidariedade já era uma dimensão "indimensionável" dos direitos económicos, sociais e culturais. Precisamente por isso, preferem hoje os autores falar de três dimensões de direitos do homem (E. Riedel) e não de "três gerações". CANOTILHO, José Joaquim Gomes. Direito constitucional e teoria da constituição. 7. ed. Coimbra: Almedina, 2003, p. 386-387. (grifos do autor).

${ }^{29}$ Complementa Vieira de Andrade, Assim nasceu a ideia dos direitos sociais, enquanto direitos a prestações estaduais - direitos de 2. ${ }^{a}$ geração ou, quanto a nós, de $3 .^{\text {a }}$, se intercalarmos os direitos de participação política -, através dos quais se visa assegurar a todos os cidadãos uma existência condigna. E, nessa linha de desenvolvimento, não se estranha que o objectivo de criar as condições efectivas de realização da dignidade da pessoa humana venha a incluir prestações estaduais destinadas a garantir, em geral, o bemestar e a qualidade de vida das pessoas. ANDRADE, António Carlos Vieira de. Os direitos fundamentais e o direito do desporto. In: BARBOSA, Nuno; COSTA, Ricardo. II Congresso de direito do desporto. Coimbra: Almedina, 2007, p. 24. 
realidade, os direitos de $3^{\mathrm{a}}$ e $4^{\mathrm{a}}$ dimensões, intentam dimensionar o concretamente indimensionável na $2^{\mathrm{a}}$ dimensão, por conseguinte, o direito ao desporto é resultante das três dimensões repontadas acima ${ }^{30}$.

No Brasil, a "constituição cidadã" de 1988 açambarcou variadas propostas de introdução de novos direitos, sendo inadiável, incontornável, dir-se-á mesmo irresistível, a previsão de um dispositivo destinado ao desporto. Ressalte-se neste ponto, que a luta, a reivindicatória ou o intento da constitucionalização desportiva brasileira se personificou resumidamente em dois cearenses: o desportista Aécio de Borba Vasconcelos e o jusdesportista Álvaro Melo Filho, este no âmbito jurídico e aquele no panorama política.

Nesse compasso, combatemos com aspereza aqueles críticos reducionistas de plantão, ao propalarem que "a inserção do direito ao desporto seria menosprezível, sob o argumento de que a nossa Magna Carta é extremamente formal e analítica, por isso, seria desprezível descer à detalhes protetores, por mero interesses de cartolas do futebol brasileiro," pois consoante redigimos no parágrafo anterior, inexistiu grande lobby no Brasil acerca da constitucionalização desportiva, quando muito, o que se alvejava era esculpir o direito ao desporto e resolver a questão da jurisdição dos conflitos tipicamente desportivos (disciplina e organização técnica de competições).

Adite-se, que o fenômeno desportivo não poderia ser marginalizado da Lei Suprema brasileira, na medida em que a tendência mundial de constitucionalizar o desporto exerceu, à época, uma robusta inspiração na previsão constitucional do direito ao desporto e rejeitá-lo seria um incomensurável retrocesso do Poder Constituinte, além de demonstrar uma falta de atualização em relação a garantia de um neófito direito social fundamental. ${ }^{31}$

\footnotetext{
${ }^{30}$ Abona a doutrina constitucionalista brasileira, A visão dos direitos fundamentais em termos de gerações indica o caráter cumulativo da evolução desses direitos no tempo. Não se deve deixar de situar todos os direitos num contexto de unidade e indivisibilidade. Cada direito de cada geração interage com os das outras e, nesse processo, dá-se à compreensão. BRANCO, Paulo Gustavo Gonet et al. Curso de direito constitucional. 4. ed. São Paulo: Saraiva, 2009, p. 268.

${ }^{31}$ Por se tratar de uma atividade que envolve a todos, direta ou indiretamente, como realização individual e/ou coletiva, era irreversível a necessidade de outorga do "status" constitucional ao desporto. Mas, por inexplicável preconceito, foi o desporto criminosamente omitido e marginalizado de todas as anteriores Constituições brasileiras, olvidando-se a expressiva opinião de Cagical de que, embora não se viva numa sociedade desportiva, pode-se afirmar que há hoje uma sociedade desportivizada. Outrossim, esta concretização constitucional das linhas-mestras do desporto não apenas resgata parte de dívida sócioeducativo-cultural que se vem acumulando, mas igualmente favorece o surgimento de uma nova sociedade reclamada por todos, constituída de indivíduos participantes, independentes e democráticos. MELO FILHO, Álvaro. O desporto na ordem jurídico-constitucional brasileira. São Paulo: Malheiros, 1995, p. 38-39. (grifos do autor).
} 
Segue abaixo alguns países ${ }^{32}$ que antecederam o Brasil na constitucionalização do desporto:

1. Constituição da Grécia de 1975, artigo 16;

2. Constituição da República Portuguesa de 1976, artigo 79. ;

3. Constituição da Espanha de 1978, artigos 43 e 148;

4. Constituição Uruguaia de 1966, reformada em 1976, artigo 71.

Em todo esse escopo, se afigurou o caminho para uma das maiores "vitórias" constituintes, o fincamento do desporto como um direito sócio-fundamental, sem o qual a Constituição brasileira esmaeceria de um dos mais complexos e sublimes direitos fundamentais hodiernos.

\section{DiReITO Ao DESPORTO, POR QUE UM DIREITO SÓCIO-FUNDAMENTAL?}

O esporte é provido de uma predominante naturalidade social, capaz de promover transformações e transcendências sociais de integração da humanidade, por tais assinaláveis características, o desporto retrata a principal atividade polifacetada do gênero lazer, movimentador de emoções, descontrações saudáveis ao homem, sendo inquestionavelmente um direito social fundamental. ${ }^{33-34}$

Asseveramos que o legislador constituinte prescreveu a seção III "Do Desporto" ao lado das seções "Da Educação", "Da Cultura", "Da Assistência Social", "Da Previdência Social", "Da Saúde", etc., todos no título "Da Ordem Social", denotando o caráter garantidor do direito ao desporto, como um direito social.

32 Dados dos países europeus pequisados em MESTRE, Alexandre Miguel. O desporto na constituição europeia: o fim do "dilema de hamlet". Coimbra: Almedina, 2004, p. 31-32. Dados do Uruguai colhidos em DOMÍNGUEZ, Andrés Gil., op. cit., 2001, p. 29.

${ }^{33}$ Há de realçar-se ser irrecusável que o reconhecimento constitucional do desporto, que obtivemos especialmente com a inclusão do art. 217 na Constituição Federal de 1988, implica na sua conexão direta e imediata com o conjunto de direitos e liberdades fundamentais reconhecidos pela Lex Magna, entre os quais ressaem a autonomia desportiva e a liberdade de associação. Sobre esses postulados constitucionais assenta-se toda a estruturação e instrumentalização do ordenamento jurídico-desportivo brasileiro, como condição necessária e inarredável para a sua juridicidade e constitucionalidade. MELO FILHO, Álvaro. O novo direito desportivo. São Paulo: Cultural Paulista, 2002, p. 17.

${ }^{34} \mathrm{~A}$ ordem jurídico-constitucional portuguesa inscreve o direito à cultura física e ao desporto num plano de direitos fundamentais identicamente ao ocorrido no Brasil, atesta Manuel Meirim: Portugal apresenta ao nível constitucional a mais impressiva recepção do direito ao desporto. Consta ela, desde logo e como já se fez referência, do art. $79 .^{\circ}$, onde o desporto é considerado como um direito fundamental de todos.

Nos artigos $64 .^{\circ}, \mathrm{n} .{ }^{\circ} 2$, alínea b), e $70 .^{\circ}, \mathrm{n} .^{\circ} 1$, alínea d), da lei fundamental, a actividade desportiva configura-se, respectivamente, como um meio de alcançar outro direito fundamental (direito à saúde) e como um direito especialmente protegido (no segmento da juventude). MEIRIM, José Manuel. Lei de bases do desporto anotada. Coimbra: Coimbra Editora, 2005, p. 20. (grifos do autor). 
A outra estirpe constitucional do desporto é o seu evidenciado cunho de direito fundamental, bastando para tanto, realizarmos uma hermenêutica sistemática a respeito do art. $5^{\circ}, \S 2^{\circ}{ }^{35}$, que dimana ser os direitos e garantias fundamentais capitulados no art. $5^{\circ}$ um rol exemplificativo de direitos fundamentais, nada impedindo que outros direitos fundamentais estejam assegurados por toda a Lei Ápice, é exatamente o que ocorre com os direitos sociais do art. $6^{036}$, onde está luminosamente escrito o direito ao lazer $^{37}$, verbete minuciosamente condensado no art. $217, \S 3^{\mathrm{o}} 38$, onde se identifica novamente a palavra lazer, porém desta vez como sinonímia de desporto, consequentemente, o direito ao desporto é assentamento refletidor do direito fundamental ao lazer, revestindo-se num autônomo direito sócio-fundamental. ${ }^{39-40}$

A firmação do direito ao desporto como um direito social fundamental, encontra arrima ainda na importância dedicada à legislação desportiva por parte

${ }^{35}$ Art. $5^{\circ}$ Todos são iguais perante a lei, sem distinção de qualquer natureza, garantindo-se aos brasileiros e aos estrangeiros residentes no País a inviolabilidade do direito à vida, à liberdade, à igualdade, à segurança e à propriedade, nos termos seguintes:

$\S 2^{\circ}$ Os direitos e garantias expressos nesta Constituição não excluem outros decorrentes do regime e dos tratados internacionais em que a República Federativa do Brasil seja parte.

${ }^{36}$ Art. $6^{\circ}$ São direitos sociais a educação, a saúde, o trabalho, a moradia, o lazer, a segurança, a previdência social, a proteção à maternidade e à infância, a assistência aos desamparados, na forma desta Constituição.

37 - que os direitos sociais, antes reconhecidos apenas por indivíduos altruístas ou generosos, lograram alcançar o status de direitos fundamentais, vale dizer, a condição de direitos oponíveis erga omnes - até mesmo contra o Estado, que, ao constitucionalizá-los, dotou as suas normas da injuntividade, por menor que seja, com que esses novos direitos iniciaram a luta pela sua efetivação -, ...COELHO, Inocêncio Mártires et. al., op. cit., 2009, p. 757-758. (grifos do autor).

${ }^{38}$ Art. 217. É dever do Estado fomentar práticas desportivas formais e não-formais, como direito de cada uma, observados:

I - a autonomia das entidades desportivas dirigentes e associações, quanto a sua organização e funcionamento;

II - a destinação de recursos públicos para a promoção prioritária do desporto educacional e, em casos específicos, para a do desporto de alto rendimento;

III - o tratamento diferenciado para o desporto profissional e não-profissional;

IV - a proteção e o incentivo às manifestações desportivas de criação nacional.

$\S 1^{\circ} \mathrm{O}$ Poder judiciário só admitirá ações relativas à disciplina e às competições desportivas após esgotarem-se as instâncias da justiça desportiva, reguladas em lei.

$\S 2^{\circ} \mathrm{A}$ justiça desportiva terá o prazo máximo de sessenta dias, contados da instauração do processo, para proferir decisão final.

$\S 3^{\circ} \mathrm{O}$ Poder Público incentivará o lazer, como forma de promoção social.

${ }^{39}$ Nos referenda, Gomes Canotilho e Vital Moreira em relação à semelhante constitucionalização desportiva em Portugal: Tal como outros preceitos relativos aos direitos económicos, sociais e culturais, também este comporta duas partes: a primeira reconhece o direito à educação física e ao desporto como direito fundamental dos cidadãos de natureza social $\left(\mathrm{n}^{\mathrm{o}} 1\right)$; a segunda enuncia as principais incumbências do Estado, lato sensu (incluindo as diversas manifestações do poder público) para dar satisfação e esse direito $\left(n^{\circ} 2\right)$. Entre elas hão-de, naturalmente, contar-se a inclusão da educação física nos programas escolares, a formação de monitores e orientadores desportivos, a edificação de campos e recintos desportivos, o apoio às colectividades desportivas, e aos atletas, etc. CANOTILHO, J. J. Gomes; MOREIRA, Vital. Constituição 
da Carta Superior, ao determinar competência legislativa concorrente da União, Estados e Distrito Federal para legislar em matéria desportiva, consoante expõe clarividentemente $\mathrm{o}$ art. $24, \mathrm{IX}^{41}$.

Dessarte, à luz da nossa Constituição Federal o direito ao desporto possui inapelavelmente uma feição sócio-fundamental incomparável a outros direitos sociais, pois fruto da versão dual do lazer disposto no art. $6^{\circ} \mathrm{em}$ comunhão com o art. $217, \S 3^{\circ}$, se revela um direito social fundamental.

\section{F- Direito ao Desporto}

O manancial, as traves-mestras, o mandamento nuclear de todo o arcabouço jurídico-desportivo brasileiro, estudado e pesquisado intensamente na disciplina de Direito Desportivo, tem supedâneo no art. 217, seção específica da Carta Superior, assim como o Direito do Trabalho que tem a sua viga-mestra nos arts. $6^{\circ}$ a 11 , o Direito Ambiental que se edifica no art. 225 e o Direito Administrativo que se entabula nos arts. 37 a 43, dentre outras tantas matérias advindas de normas da nossa vigente Constituição Federal.

Nessa assertiva, não vamos nos dedicar ou se debruçar a respeito da materialidade dos ditames principiológicos do direito ao desporto previstos ao longo dos incisos e parágrafos do art. 217, na medida que esse não é o foco principal desse trabalho científico, conquanto, iremos nos adstringir a explanação concisa do significado de cada extrato petrificado no referido dispositivo, identificando o seu correspondente princípio.

\subsection{Garantia AMPla do direito aO desporto (Universalidade)}

O mandamento 217, caput da Lei Suprema garante o direito ao desporto em todas as suas dimensões, como um direito social fundamental inexpugnável, inafastável, indispensável, no sentido de possibilitar a prática desportiva escolar, de lazer, terapêutica, de recuperação da saúde física, de ressocialização dos detentos, de estímulo na vida provecta, de promoção da cultura (atividade esportiva

da república portuguesa anotada. 4. ed. v. I. Coimbra: Coimbra Editora, p. 933-934. (grifos dos autores). Sublinha timidamente, mas de maneira lúcida, Alexandre de Moraes, O direito constitucional às práticas desportivas conjuga-se com o direito à vida, à saúde, ao lazer, em busca da efetivação do bem de todos, objetivo fundamental da República (CF, art. $3^{\circ}$, IV), devendo, portanto, ser interpretado de forma razoável e educativa, proibindo-se o incentivo a pseudo-esportes de efeitos perniciosos e atentatórios ao princípio da dignidade da pessoa humana. MORAES, Alexandre de. Constituição do Brasil interpretada. 3. ed. São Paulo: Atltas, 2003, p. 1998.

${ }^{41}$ Art. 24. Compete à União, aos Estado e ao Distrito Federal legislar concorrentemente sobre: IX - educação, cultura, ensino e desporto; 
artística), de incentivo ao exercício profissional do esporte, como mais um campo de trabalho, fonte de renda num Mundo vivido em recessão, (motivação, exemplo para os jovens praticarem esportes).

Em simultaneidade, o direito ao desporto garantido no excerto supramencionado, tem uma amplitude difusa, coletiva e individual ao mesmo tempo, devendo-se interpretá-lo como um bem de cada um e de todos do povo concomitantemente, incluindo aqueles que possuem alguma deficiência física ou mental, protegendo o acesso e a continuidade das atividades esportivas em seu aspecto mais amplo. ${ }^{42}$

Nesse caput do art. 217 da CF/88, se traduz o preceito da universalidade, também reconhecido, positivado pelo COI, FIFA, outros Estados Democráticos de Direito ${ }^{43}$, que por meio dele, garantem a pratica desportiva à todos, indiscriminadamente e na sua conceptiva mais abrangente, promove a paz, união entre pessoas e povos.

\subsection{Autonomia das entidades desportivas (Autonomia Desportiva) ${ }^{44}$}

A autonomia desportiva é um direito implantado no art. 217, I da Lei Magna, que outorga às entidades desportivas, constituídas sob a personalidade jurídica de associações sem fins lucrativos, a liberdade de se autoconstituir, auto-organizar e autofuncionar ou autogerir, com intervenção mínima do Estado (Poderes Públicos em geral).

Este direito imanta no ordenamento jurídico-desportivo brasileiro o sistema jus-privatista ou não-intervencionista ${ }^{45}$, onde se caracteriza a intervenção mínima do Estado na regulação e movimentação da prática desportiva formal, e, em casos

42 Elucida o direito ao desporto no caput do art. 217 da CF/88, Álvaro Melo filho em suas obras MELO FILHO, Álvaro., op. cit., 1990, p. 9 e ss., MELO FILHO, Álvaro., op. cit., 1995, p. 41-49.

${ }^{43}$ No ordenamento jurídico português, assinala Manuel Meirim, $\mathrm{O}$ segmento Todos têm direito à actividade física e desportiva consagra a universalidade do direito, ao mesmo tempo que - embora afastando-se da semântica constitucional - precipita o conteúdo do.$^{\circ} 1$ do artigo $79 .^{\circ}$ (Todos têm direito à cultura física e ao desporto). MEIRIM, José Manuel. Lei de bases da actividade física e do desporto: estudos, notas e comentários. Coimbra: Coimbra Editora, 2007, p. 125.

${ }^{44}$ A respeito da autonomia desportiva, MELO FILHO, Álvaro., op. cit., 1990, p. 22-26, 45 e ss. MELO FILHO, Álvaro., op. cit., 1995, p. 34 e ss., MELO FILHO, Álvaro et al. Direito desportivo. Campinas-SP: Mizuno, 2000, p. 171 e ss., MELO FILHO, Álvaro. Direito desportivo no limiar do século XXI. Fortaleza: ABC Fortaleza, 2000, p. 31 e ss., MELO FILHO, Álvaro., op. cit., 2002, p. 63 e ss., MELO FILHO, Álvaro. Autonomia de organização e funcionamento das entidades de prática desportiva e de direção do desporto brasileiro. In: AIDAR, Carlos Miguel. Curso de direito desportivo. São Paulo: Ícone, 2003, p. 55 e ss.

${ }^{45}$ Existem três tipos de sistemas jurídicos desportivos no Mundo, o sistema adotado por Portugal, França, Espanha e Itália por exemplo, denominado de jus-publicista, publicista, ou ainda, intervencionista. O sistema 
pontualíssimos, na atividade esportiva não-formal. Nada obstante, essa sistemática atribui às associações desportivas, mormente as entidades administrativas (federações), pessoas jurídicas de direito privado, algumas prerrogativas típicas, assemelhadas aos casos especiais dos Sindicatos e dos Partidos Políticos.

$\mathrm{O}$ que inexoravelmente se pretendeu com esse verbete constitucional, foi proporcionar às entidades desportivas uma administração e organização do desporto com bem menos Estado e mais iniciativa privada, viabilizando uma maior coordenação dos entes esportivos nacionais com os entes desportivos internacionais na manutenção da prática desportiva dinâmica, uniforme e transnacional, evitando quaisquer estagnações e distorções orgânico-esportivas no plano brasileiro em relação ao espaço universal das atividades desportivas.

Essa premissa do art. 217, I da $\mathrm{CF} / 88$, encarta o princípio da autonomia desportiva, subdivisão sui generis, ramificação principiológica do tronco fundamental da liberdade de associação (art. $5^{\circ}$, XVII a XXI da $\mathrm{CF} / 88$ ), que similarmente ao princípio da Unidade Sindical (art. $8^{\circ}$, II da CF/88), aos princípios da autonomia e representatividade dos Partidos Políticos (art. 14, $\S \S 1^{\circ}$ e $2^{\circ}$ da Lex Legum) exerce a sua autonomia, unidade e representatividade em matéria de administração desportiva.

Adicionamos, para findar, que apenas uma entidade de administração do desporto (federação desportiva) pode existir por Estado da Federação brasileira (Federação Paulista de Futebol/FPF, Federação de Futebol do Estado do Rio de Janeiro/FERJ, Federação Cearense de Futebol/FCF, etc.), sendo permitida mais uma associação administrativa-desportiva, representativa da Unidade Federada/Brasil (princípio da Unidade/Unicidade, exs.: Confederação Brasileira de Futebol/CBF, Confederação Brasileira de Futebol de Salão/ CBFS, Confederação Brasileira de Voleibol/CBV, Confederação Brasileira de Basquetebol/CBB, etc.) pautadas no inc. I do art. 217, amálgama em que todas essas federações esportivas estão hierarquizadas, adstritas a um ente maior, uma federação desportiva internacional em mais alto grau, se submetendo por adesão, às suas normas e regras universais da respectiva modalidade (princípio do Monopólio, ex.: Fédération Internationale de Football Association/FIFA, Fédération Internationale de Volleyball/FIVB, Fédération Internationale de Basketball/FIBA, Fédération Internationale de 1'Automobile/FIA, etc... $)^{46-47}$.

Misto, vislumbrado na Suíça e o jus-privatista (não-intervencionista), primariamente desenvolvido na Inglaterra e Alemanha, escolhido pelo nosso Constituinte. Assim nos explica o Mestre Álvaro em seu livro MELO FILHO, Álvaro. Direito desportivo: novos rumos. Belo Horizonte: Del Rey, 2004, p. 8-10, 167.

46 Tradução na ordem: Federação Internacional do Futebol Associado/FIFA, Federação Internacional de Voleibol/ FIVB, Federação Internacional de Basquetebol/FIBA, Federação Internacional do Automobilismo/FIA.

${ }^{47}$ Acerca dessa temática, vale indicar: REI, Maria Raquel et al. Estudos de direito desportivo. Coimbra: Almedina, 2002, p. 44-45., CARRO, Miguel Cardenal; SILVERO, Emílio García et al. Régimen mercantil, 


\subsection{DESTINAÇÃO PRIORITÁRIA DE RECURSOS PÚBLICOS (Prioridade dos Recursos Públicos)}

No art. 217, II da CF/88, se estabelece a obrigação do Estado em priorizar a destinação de recursos públicos ao desporto educacional, restando em uma esfera inferior a verba direcionada ao esporte de alto rendimento. Nesse instante, é conveniente esclarecermos que esse postulado se refere a uma aplicação pecuniária prioritária dos órgãos públicos ao desporto-educação, não significando que os investimentos públicos somente possam ser enviados ao desporto educativo, pois o texto constitucional é lúcido ao proporcionar a investida de pecúnia pública no esporte de alto rendimento. Assinalamos ainda, que o radical composto da palavra alto rendimento exprime abrangentemente que verbas públicas poderão em algumas ocasiões serem ofertadas ao desporto-competição e a interpretativa deve ser mais além, pois a aplicabilidade pecuniária no desporto profissional também é possível, bastando ter em mente que uma atividade esportiva de alto rendimento pode ser profissional.

A melhor hermenêutica constitucional que se deve extrair da subscrição supracomentada é o entendimento extensivo da palavra desporto educacional, para que se coadune com o caput e inc. III do artigo 217 na consecução de incentivar financeiramente quaisquer tipologias de atividades esportivas nãoformais, evidentemente, em sincronia com a realidade-possibilidade econômica estatal e necessidade social.

Com efeito, o princípio da prioridade de recursos públicos determina que, através do orçamento público específico, singular, o Estado tenha a primazia de desenvolver o esporte como objeto de transformação social, sem contudo, vilipendiar a importância de apoiar o desporto de alto rendimento (de obtenção de resultado e profissional) como peças-chaves na oferenda de lazer à população.

Vale salientar, que em um espetáculo desportivo, o apoio público é fundamental para a sua realização, a logística estatal na segurança e orientação do espectador esportivo, dentre outras questões, são indissociáveis de um evento de médio a grande monta e o auxílio do Poder Público revela a sua boa intenção em promover o lazer através do esporte.

\subsection{TRATAMENTO DifERENCIAdO AO DESPORTO PROFISSIONAL E NÃO-PROFISSIONAL (DIFERENCIAÇÃo)}

O direito a um tratamento diferenciado, relacionado ao desporto profissional e não-profissional, consignado no art. 217, III da CF/88, firma um aprimoramento 
do Estado na aplicação das finanças públicas e uma organização maior na verificação das necessidades reais de cada setor da atividade esportiva.

O tão reconhecido e propalado princípio da diferenciação retrata uma verídica isonomia, igualdade em matéria desportiva, pois é sabido que igualdade/ isonomia não significa "tratar todas as pessoas de forma igual, mas tratar os iguais de forma igual e os desiguais de forma desigual", ou seja, entender a realidade e a necessidade é preponderante para uma boa condução do serviço desportivo por parte do Estado.

Nesse esteio, o Poder Público não poderá padronizar o seu tratamento para todo exercício esportivo, ao anverso, deverá sempre dedicar técnicas de estudos acurados em diversos meios desportivos, prospectando as especificidades, adequabilidades, necessidades de cada particularidade setorial esportiva para aperfeiçoar o emprego de gastos públicos e otimizar a orgânica do desporto local, regional e nacional. A correta aplicação do princípio da diferenciação executa o tratamento de justa medida devido ao cidadão-desportista e às coletividades esportivas.

\subsection{ProteÇão e inCentivo Às MANifestaÇões ESPORTIVAS DE CRIAÇÃO NACIONAL (Proteção e incentivo desportivo nacional)}

O legislador constituinte ao proteger e incentivar as manifestações desportivas genuinamente nacionais visa proteger a cultura da atividade esportiva criada em nosso país, pois sabemos que esportes como o futsal e a capoeira são verdadeiros retratos consuetudinários da nossa sociedade, os valores históricoculturais são vivos nessas atividades esportivas..$^{48}$

Desta maneira, o princípio da proteção e incentivo desportivo nacional apregoa ao Estado o dever protetivo da originalidade desportiva brasileira, ao mesmo passo que patrocina a profusão cultural-esportiva do Brasil no espaço internacional, nacionalizada nas pessoas e instituições de caráter nacional (representantes brasileiros). ${ }^{49}$

\footnotetext{
${ }^{48}$ A capoeira é uma modalidade desportiva de luta que se remete a um passado colonial, onde a resistência escravagista negreira se mistura no seio de uma sociedade multiracial de ginga também polifacetada, representando não apenas os nossos ascendetes africanos, mas envolvendo a evolução da arte-macial a partir das danças e culturas européias, latinas, norte-americanas, asiáticas e até mesmo oriundas do povo da Oceânia. O futsal reproduz a paixão indimensionável de um povo pelo futebol, mas como este se originou em localidade estrangeira, a necessidade de reinventar, recriar o futebol que se caracteriza no curto espaço e estrutura de prática conjugal ao drible curto da etnia brasileira.

${ }^{49}$ Acerca da proteção e incentivo dos esportes de origem nacional, nos remetemos a MELO FILHO, Álvaro., op. cit., 1990, p. 30-31.
} 


\subsection{Previsão constitucional da Justiça Desportiva (ESGOTABILIDADE DA JUSTIÇA DESPORTIVA E JURISDIÇÃO PRÉVIA E TEMPORÁRia da Justiça Desportiva) ${ }^{\mathbf{5 0}}$}

O redator constitucional do artigo 217 da nossa Lex Fundamentalis num ineditismo, pioneirismo e inovação, animus novandi, previu nos $\S \S 1^{\circ}$ e $2^{\circ}$ do referido mandamento, a Justiça Desportiva com uma natureza singular, peculiar, especialíssima.

Esta é uma oportuna e breve situação para desmistificarmos, desestigmatizarmos novamente, as afirmativas indigitadas de alguns colegas que insistem em considerar a Justiça Desportiva como um ente inconstitucional ou menosprezível, afigurando-se na decisória do Superior Tribunal de Justiça ${ }^{51}$ como um vazio jurídico.

Em outras oportunidades descritas em nota de rodapé, nos empenhamos na redação relativa à previsão constitucional e à natureza da Justiça Desportiva, criticando contundentemente a aresta do STJ, portanto, nessa tarefa, a nós incumbe reafirmar que a existência da Justiça Desportiva é tão constitucional quanto quaisquer outras previsibilidades da Lei Maior brasileira, pois a ratio fundamentalis do constituinte foi autorizar uma Justiça do Desporto às margens do Poder Judiciário, perfazendo uma exceção, excepcionalidade veiculada pelo Poder Constituinte Originário aos princípios da inafastabilidade do Poder Judiciário (princípio da tutela jurisdicional ou da jurisdição una) e do juiz natural, que representam a monopolização da atividade jurisdicional do Estado. Constatese, que por viabilidade oriunda do Poder Constituinte Originário, o constituinte autoriza, outorga a instituição de uma Justiça dotada de atipicidade jurisdicional, fora do Poder Judiciário.

Nesse modelo, há divergências acerca da natureza ampla da Justiça Desportiva brasileira, a teoria que predomina é do próprio redator do art.

\footnotetext{
${ }^{50}$ Permita-nos remissão a RAMOS, Rafael Teixeira. Justiça desportiva brasileira: natureza e algumas críticas estruturais. Revista aranzadi de derecho de deporte y entrenimiento. Navarra: Thomson Aranzadi, n. 20, p. 151-173, 2007., RAMOS, Rafael Teixeira. A relação da justiça desportiva com o poder judiciário e alguns métodos extrajudiciais de resolução de conflitos no Brasil. Desporto \& Direito: revista jurídica do desporto. Coimbra: Coimbra Editora, n. 15, p. 467-487, mai/ago, 2008., RAMOS, Rafael Teixeira. Justiça desportiva brasileira: natureza, relação com o poder judiciário e os métodos extrajudiciais de resolução de conflitos. Revista Brasileira de Direito Desportivo. São Paulo: IOB, n. 13, p. 27-48, jan/jun, 2008., RAMOS, Rafael Teixeira; MAGALHÃES, Larissa Navarro Benevides de. Autonomia e independência da justiça desportiva brasileira. Revista Brasileira de Direito Desportivo. São Paulo: IOB, n. 14, p. 68-75, jul/dez, 2008.

${ }^{51}$ STJ - Tribunal de Justiça Desportiva. Natureza Jurídica. Inocorrência de conflito. 1. Tribunal de Justiça Desportiva não se constitui em autoridade administrativa e muito menos judiciária, não se enquadrando a hipótese em estudo no art. 105, I, g, da CF/88 (STJ - 2 ${ }^{\mathrm{a}}$ Seção - Conflito de atribuição n ${ }^{\circ}$ 53/SP - Rel. Min. Waldemar Zveiter, Diário da Justiça, Seção I, 3 ago. 1998, p. 66). (grifos nossos).
} 
217, Álvaro Melo Filho que preleciona ser a Justiça do Desporto de natureza administrativa e privada, enquanto Marcilio Krieger e Paulo Schimitt se expressam vagamente a respeito do assunto, mas se inclinam para a doutrina dominante de Álvaro Melo Filho. A nossa tese constata uma natureza mista, ao sustentarmos que existe formação estrutural privada/pública e ao mesmo tempo atribuições e atividades jurídico-administrativas.

$\mathrm{O} \S 1^{\circ}$ do art. 217, apresenta a delimitação jurisdicional da Justiça do Desporto, ao circunscrever as suas matérias relativas às disciplinas e às competições desportivas (materialidade puramente, tipicamente, meramente esportivas), prevendo ainda o esgotamento das instâncias da Justiça Desportiva, como pressuposto processual constitucionalizado, para se demandar no Poder Judiciário.

O princípio do exaurimento/esgotabilidade da Justiça do Desporto concebe a proteção da jurisdição dessa Justiça, ao proibir que se movimente o Poder Judiciário antes de se percorrer todos os órgãos jurisdicionais desportivos.

Em seguida, no art. $217, \S 2^{\circ}$ da $\mathrm{CF} / 88$ se determina o prazo da jurisdição prévia da Justiça do Desporto, minudenciando o prazo máximo de sessenta dias para a Justiça Desportiva proferir decisão final, sob pena de as partes poderem ajuizar as querelas esportivas (disciplina e competições desportivas) no Poder Judiciário, antes mesmo de se exaurir as instâncias da Justiça Desportiva.

O princípio da jurisdição prévia e temporária assenta uma garantia mínima à Justiça do Desporto no exercício das suas atividades jurisdicionais outorgadas pela Constituição, protegendo a Justiça Desportiva de possíveis usurpações em sua jurisdicionalidade.

No entanto, cabe ressalvarmos, que o redator do art. $217, \S \S 1^{\circ}$ e $2^{\circ}$ sabiamente pretendeu instaurar uma Justiça especializada, célera e dinâmica, assim como é a atividade desportiva, mas acrescentou certamente a instituição de uma via judicante doméstica para a matéria esportiva, na tentativa máxima de mediar o eterno conflito entre o desestímulo da FIFA e COI aos seus filiados de pleitear demandas estritamente desportivas no Poder Judiciário e a proibição dos Estados Democráticos de Direito de se afastar dissídios de quaisquer naturezas da apreciação dos órgãos jurisdicionais estatais.

Geralmente, os associados, membros da sistêmica desportiva nacional e internacional, preferem se conformar com as decisões do ambiente judicante desportivo, em raras exceções há descontentamentos e movimentação da máquina do Poder Judiciário, quando isso ocorre, sob fortes ameaças da FIFA ou COI, os filiados esmorecem em suas tentativas, em outros raríssimos casos, quem cede são os entes desportivos internacionais aqui citados. 


\subsection{INCENTIVO AO LAZER COMO FORMA DE PROMOÇÃO Social (Promoção Social)}

Em última abordagem, o $\S 3^{\circ}$ do art. 217 subscreve o mencionado anteriormente nesse tema, a utilização da atividade desportiva como concretização atrial do direito ao lazer, ou a utilidade esportiva como um dos métodos mais fungíveis de praticidade do direito ao lazer à população, devido pelo Estado (art. $6^{\circ}$ da CF/88).

Acresça-se, que o ditame em tela discorre sobre o incentivo ao lazer como forma de promoção social, curioso notar que não é por mero acaso que o legislador constituinte inserta no art. $217, \S 3^{\circ}$ a terminologia lazer, leia-se também esporte, demonstrando-se ser este espécie da generalidade lazer.

Impende destacar, que o cultivo do esporte como lazer integrado às linhas assecuratórias do caput, incs. II, III e IV do reinterado art. 217, tem o condão de combater a violência (criminalidade) e afastar a discriminação em quaisquer gradações. ${ }^{52-53}$

Em síntese, o princípio da promoção social tenciona elevar o esporte a uma das principais categorias de lazer, enquadrando sistematicamente o direito ao desporto num rol de direitos sócio-fundamentais, sendo um dos vetores, canais movimentadores do desenvolvimento social.

\section{(i. Ensino do Direito Desportivo/Direito do Desporto: UMA URGÊNCIA PARA A ACADEMIA JURÍDICA CEARENSE}

Ante todo o apreendido acima, acentuando que há um mercado cada vez mais ascendente no campo esportivo, sedento por especialistas, declarando ainda que o estudo do Direito Desportivo não se limita ao examinado ao longo desse

\footnotetext{
${ }^{52}$ Nesse apanágio, a Constituição portuguesa foi mais explícita no combate a violência (art. $\left.79^{\circ} / 2\right)$. Comentam Gomes Canotilho e Vital Moreira, Nas tarefas públicas, a Constituição destaca especialmente a prevenção da violência no desporto ( $\mathrm{cfr}$. $\mathrm{L} \mathrm{n}{ }^{\circ}$ 38/98), obrigando o Estado adoptar as medidas necessárias, apropriadas e proporcionais à prevenção e punição de formas antidesportivas (violência, corrupção, dopagem, discriminação social). CANOTILHO, J. J. Gomes; MOREIRA, Vital., op. cit., 2007, p. 934. (grifos dos autores).

${ }^{53}$ No ordem jurídica espanhola, merece referência: La Ley 19/2007, de 11 de julio, contra la violencia, el racismo, la xenofobia y la intolerancia en el deporte, pretende regular en un solo texto legal todas las medidas de lucha contra tales comportamientos, partiendo de la experiencia en la lucha contra la violencia en el deporte. El modelo gira de nuevo sobre un órgano administrativo, la Comisión Estatal contra la Violencia, el Racismo, la Xenofobia y la Intolerancia en el Deporte, que sustituye a la Comisión Nacional para la Prevención de la Violencia en los Espectaculos Deportivos hasta ahora existente. JORQUERA, Antónia Perelló. La Comisión Estatal contra la Violencia, el Racismo, la Xenofobia y la Intolerancia en el deporte: organización, composición y funcionamiento. Revista aranzadi de derecho de deporte y entrenimiento. Navarra: Thomson Aranzadi, n. 24, p. 93-106, 2008.
} 
texto, obtendo o desporto as suas mais diversas problemáticas e sendo nítido que há um considerável clamor dos acadêmicos em pelo menos ter acesso à cognição jusdesportiva, é que pugnamos pela urgência de se implementar nas Faculdades de Direito do Ceará, uma quantidade maior de cursos, especializações e em breve a introdução da cadeira opcional de Direito Desportivo nas grades curriculares. ${ }^{54}$ Tal urgência é pressionada pela própria sociedade, onde se verifica o exponencial surgimento de fenômenos, acontecimentos esportivos e se a academia jurídica cearense não despertar brevemente, considerar-se-á um retrocesso no ensino do Direito no Estado do Ceará.

\section{ConsideraÇões Finais}

Os contornos resumidos do Direito Desportivo e do Direito ao Desporto, enquanto apresentação da matéria jurídico-desportiva é um pontapé inicial referendado na Carta Fundamental, sendo extremamente precioso nesses aproximadamente vinte e um (21) anos de história da atual Constituição Federal. Em matéria estritamente jurídico-desportiva, podemos comemorar alguns avanços relativos à confirmação do direito ao esporte, todavia, admitamos que a prática demonstra um longo caminho a ser percorrido, além de ser imprescindível um maior aprofundamento na difusão e fomento da área de Direito Desportivo.

\footnotetext{
${ }^{54}$ Nesse contexto, é cediço que os cursos de Direito não podem continuar refratários e indiferentes à relevância do Direito Desportivo, sob pena de transformar a estrutura curricular em uma "peça jurassicamente ossificada" ou de operacionalizar um projeto pedagógico distanciado do mercado de trabalho e impermeável às mudanças.

O fato de categorizar-se o Direito Desportivo na grade curricular como matéria "obrigatória" ou "optativa", não afeta sua importância pedagógica que decorre de exigência legal de inserção de "novos saberes" e "novos direitos" como componentes dos currículos jurídicos. Dentro dessa perspectiva, enquanto disciplina curricular, o Direito Desportivo, qualquer que seja a tipologia ou método de aula adotado, deve ser um "diálogo de aquisições recíprocas" entre professor e aluno, ou entre estes, para desenvolver o espírito lógico, o poder de persuasão, a capacidade de decisão e de reação na resposta a dar aos argumentos alheios e o respeito à opinião dos outros, possibilitando a abertura de "novos horizontes" da problemática jusdesportiva. Outrossim, ao transpor os muros das Universidades, o Direito Desportivo, como disciplina curricular, não pode olvidar as exigências múltiplas e crescentes daqueles que irão atuar na esfera jurídico-desportiva, cabendo-lhe capacitá-los a enfrentar o "dilúvio" ou "avalanche" de novas normas jurídicas com que é diariamente confrontado e prepará-los para acompanhar e interpretar as frequentes alterações infralegais e reformas legislativas no âmbito do desporto.

Assim, torna-se imperiosa e cogente a inclusão do Direito Desportivo como matéria dos currículos jurídicos, desdobrando-a, ou não, em disciplinas jurídicas. Esclareça-se que matéria não se confunde com disciplina, esta é continente e aquela conteúdo. A disciplina quando única, pode albergar toda a matéria correspondente, equanto a matéria comporta o desdobramento em plúrimas disciplinas, quase sempre, com a mesma denominação, acrescida de algarismos romanos como símbolos distintivos. MELO FILHO, Álvaro. Direito desportivo: aspectos teóricos e práticos. São Paulo: IOB Thomson, 2006, p. 17-18. (grifos nossos).
} 
Em resumo, as alíneas mananciais foram ministradas aos alunos da Faculdade de Direito FA7 e nesse engatinhar esperamos ter contribuído o mínimo necessário para a comprovação da importância do estudo do Direito Desportivo no Estado do Ceará, subsequentemente no Brasil.

\section{REFERÊNCIAS}

ANDRADE, António Carlos Vieira de. Os direitos fundamentais e o direito do desporto. In: BARBOSA, Nuno; COSTA, Ricardo. II Congresso de direito do desporto. Coimbra: Almedina, 2007.

BRANCO, Paulo Gustavo Gonet et al. Curso de direito constitucional. 4. ed. São Paulo: Saraiva, 2009.

CANOTILHO, José Joaquim Gomes. Direito constitucional e teoria da constituição. 7. ed. Coimbra: Almedina, 2003.

; MOREIRA, Vital. Constituição da república portuguesa anotada. 4. ed. v. I. Coimbra: Coimbra Editora.

CARRO, Miguel Cardenal; SILVERO, Emílio García et al. Régimen mercantil, laboral, fiscal, contable y económico del fútbol profesional. Barcelona: Deusto Jurídico, 2008.

DOMÍNGUEZ, Andrés Gil. El derecho al deporte y el derecho del deporte. In: NAVÍA, Ricardo Frega. Cuadernos de derecho deportivo. Buenos Aires: Ad Hoc, 2001.

EZABELLA, Felipe Legrazie. O direito desportivo e a imagem do atleta. São Paulo: IOB Thomson, 2006.

GARDINER, Simon et al. Sports Law. 3. ed. Sydney/London: Cavendish, 2006. LOUP, Jean. Les sports et le droit. Paris: Dalloz, 1930.

LYRA FILHO, João. Introdução ao direito desportivo. Rio de Janeiro: Pongetti, 1952. MEIRIM, José Manuel. A federação desportiva como sujeito público do sistema desportivo. Coimbra: Coimbra Editora, 2002.

. O direito do desporto em Portugal: uma realidade com história. In: BARBOSA, Nuno; COSTA, Ricardo. I Congresso de direito do desporto. Coimbra: Almedina, 2005.

. Lei de bases do desporto anotada. Coimbra: Coimbra, 2005.

. Temas de direito do desporto. Lisboa: Coimbra Editora, 2006.

. Lei de bases da actividade física e do desporto: estudos, notas e comentários. Coimbra: Coimbra, 2007. 
MELO FILHO, Álvaro. Direito desportivo. Fortaleza: IOCE, 1983.

. Desporto na nova constituição. Porto Alegre: Sergio Antonio Fabris, 1990.

. O desporto na ordem jurídico-constitucional brasileira. São Paulo: Malheiros, 1995.

. Novo ordenamento jurídico-desportivo. Fortaleza: ABC Fortaleza, 2000. et al. Direito desportivo. Campinas-SP: Mizuno, 2000.

. Direito desportivo no limiar do século XXI. Fortaleza: ABC Fortaleza, 2000.

. O novo direito desportivo. São Paulo: Cultural Paulista, 2002.

- Autonomia de organização e funcionamento das entidades de prática desportiva e de direção do desporto brasileiro. In: AIDAR, Carlos Miguel. Curso de direito desportivo. São Paulo: Ícone, 2003.

. Direito desportivo: novos rumos. Belo Horizonte: Del Rey, 2004.

. Direito desportivo: aspectos teóricos e práticos. São Paulo: IOB Thomson, 2006.

MESTRE, Alexandre Miguel. O desporto na constituição europeia: o fim do "dilema de hamlet". Coimbra: Almedina, 2004.

. Direito e jogos olímpicos. Coimbra: Almedina, 2008.

MORAES, Alexandre de. Constituição do Brasil interpretada. 3. ed. São Paulo: Atlas, 2003.

PESSANHA, Alexandra. As federações desportivas: contributo para o estudo do ordenamento jurídico desportivo. Lisboa: Coimbra, 2001.

REI, Maria Raquel et al. Estudos de direito desportivo. Coimbra: Almedina, 2002. RIBEIRO, Carla. Desporto para todos - crise de identidade e desenvolvimento. In: BENTO, Jorge Olímpio; COSTANTINO, José Manuel. Em defesa do desporto: mutações e valores em conflito. Coimbra: Almedina, 2007.

Periódicos

CASTRO, Luiz Roberto Martins. A natureza jurídica do direito desportivo. Revista Brasileira de Direito Desportivo. São Paulo: Editora OAB/SP, n. 1, p. 11-17, jan/ jun, 2002.

JORQUERA, Antónia Perelló. La Comisión Estatal contra la Violência, el Racismo, la Xenofobia y la Intolerância en el deporte: organización, composición y funcionamiento. Revista aranzadi de derecho de deporte y entrenimiento. Navarra: Thomson Aranzadi, n. 24, p. 93-106, 2008.

MELO FILHO, Álvaro. Direito desportivo brasileiro: retrospectiva e perspectiva. Desporto \& Direito: revista jurídica do desporto. Coimbra: Coimbra Editora, $\mathrm{n}$. 8, p. 261-276, jan/abr, 2006. 
. Da constitucionalização do desporto no Brasil. Revista aranzadi de derecho de deporte y entrenimiento. Navarra: Thomson Aranzadi, n. 24, p. 263-271, 2008. PERRY, Valed. O Direito Desportivo. Revista Brasileira de Direito Desportivo. São Paulo: Editora OAB/SP, n. 1, p. 18-26, jan/jun, 2002.

RAMOS, Rafael Teixeira. Justiça desportiva brasileira: natureza e algumas críticas estruturais. Revista aranzadi de derecho de deporte y entrenimiento. Navarra: Thomson Aranzadi, n. 20, p. 151-173, 2007.

. Justiça desportiva brasileira: natureza, relação com o poder judiciário e os métodos extrajudiciais de resolução de conflitos. Revista Brasileira de Direito Desportivo. São Paulo: IOB, n. 13, p. 27-48, jan/jun, 2008.

. A relação da justiça desportiva com o poder judiciário e alguns métodos extrajudiciais de resolução de conflitos no Brasil. Desporto \& Direito: revista jurídica do desporto. Coimbra: Coimbra Editora, n. 15, p. 467-487, mai/ago, 2008.

; MAGALHÃES, Larissa Navarro Benevides de. Autonomia e independência da justiça desportiva brasileira. Revista Brasileira de Direito Desportivo. São Paulo: IOB, n. 14, p. 68-75, jul/dez, 2008.

Sítio da Internet

PERRY, Valed. Comentários à legislação desportiva brasileira. Disponível em: $<$ http://www.estantevirtual.com.br/buscaporautortitulo/>. Acesso em: 29 abr. 2009.

\section{SPORTS LAW AND THE SPORTS RIGHT IN THE BRAZILIAN CONSTITUTION}

Abstract: The present paper has the goal to introduce Sports Law to academics of Ceará, explaining the importance of sports to our contemporary society, describing many values of sports according to our constitutional prevision and protection.

Keywords: Sports Law. Federal Constitution. Brazil. 